\title{
Nutrition Teaching in the Courses Sponsored by the Hotel and Catering Institute
}

\author{
By John Fuller, The Hotel and Catering Institute, 24 Portman Square, London, W. I
}

\section{The catering industry}

The people of these islands have in recent years often been reproached in matters gastronomic. They have been likened to Baron Munchausen's 'Cooking Animals of the Moon', who had no interest in food, but opened their stomachs at regular intervals to receive entire meals. Until recently such strictures, justly or unjustly, were applied to public consciousness of nutrition also. There are signs nowadays, however, of growing public awareness of food values, which in turn influences the hotel keepers and caterers of to-day and consequently must affect those of the future.

Hotel keeping and catering is the nation's fourth largest industry, but the industry is divided into sections, each with its own special interests and problems. The caterer's attitude to nutrition differs according as he is engaged in hotels, restaurants, industrial catering establishments, the licensed trade, transport catering, hospitals or the School Meals Service. In industrial catering, hospitals and schools, it is apparent that nutrition is a vital factor in catering as part of a welfare service. In luxury hotels and restaurants it is probable that varied and costly meals will provide few nutritional problems, though their richness may provoke digestive ones.

When, therefore, the industry sought to plan a technical educational programme, it recognized the different needs of the different fields in which caterers operate.

\section{The syllabuses}

The Hotel and Catering Institute is the professional and educational body for the hotel and catering industry; it was incorporated in 1949, rather less than 5 years after the industry began to organize itself educationally through the Catering Trades Education Committee, later to become the National Council for Hotel and Catering Education. The Institute carries forward the work begun by these two bodies, now dissolved. In 1943 there was one technical college offering courses in hotel and catering subjects conducted on trade lines, whereas there are now over a hundred, of which thirty-four offer full-time training. Such a development of technical education for the industry is impressive, though recent, for all the courses leading to the City and Guilds of London Institute examinations in catering subjects or to the Hotel and Catering Institute's own examinations, are considerably less than Io years old. Syllabuses for the courses are consequently still open to change with the accumulation of experience by both the industry receiving students and the technical colleges preparing them. The place of nutrition in Hotel and Catering Syllabuses, as in other subjects, is by no means finally determined. 
The industry, as represented by the Hotel and Catering Institute, has all the same a clear view of the type of basic training required. The City and Guilds of London Institute ' 150 ' Catering Trades Basic Training Course, a course devised in close consultation with all branches of the industry, is regarded as the ideal initial training for all types of entrants. Every section of the industry, from the small unit caterer to the large luxury hotel keeper, has agreed that this basic training is most desirable, if not essential, whether students later follow a craft or professional vocation in the industry or go to welfare catering or international style restaurants. Thus the industry has uncompromisingly decided that wherever possible all those who enter hotel keeping and catering in the future shall undergo the same preliminary training.

\section{Nutrition and cooking}

While the ' 150 ' Catering Trades Basic Training Course naturally lays a considerable emphasis on craft skills, particularly cookery, the Course provides for instruction in such subjects as calculations for caterers, hygiene, gas, water and electrical services, commodities and food values. Nutrition, albeit at a basic and elementary level, is introduced into the curriculum of all students, whether full or part time, as soon as they come within the industry's technical training system.

The study of commodities, for example, is designed to develop an interest in raw and manufactured foodstuffs in general use and to indicate their suitability for various purposes. As a rule the teaching of food values is linked with the instruction given in other parts of the course on practical cookery, food preparation and storage. The primary aim is usually to relate simple nutrition to kitchen and catering practice rather than to provide formal lectures on elementary dietetics. Thus food values are given a prominent place in the teaching of appropriate methods of vegetable storage, preparation and cookery to conserve important nutrients. Later, in the planning of balanced menus, which to a caterer includes balance of colour, flavour and texture, the student also learns something of the vital importance of dietetic balance. It is thus difficult to segregate nutrition as a subject in the basic catering training, for it is an integral part of almost all classes, theoretical or practical.

\section{Varied approaches to nutrition}

In a basic catering training course for full-time students at a typical technical college in the London area, $54 \mathrm{~h}$ of the year are devoted to the direct teaching of nutrition, and at the same college part-time students are given $18 \mathrm{~h}$ direct instructions in simple nutrition out of a total of 60 devoted to commodities. Again, this does not take into account the teaching of nutrition known to be integrated with the teaching of various aspects of food storage, preparation and cookery. It should, perhaps, be stressed here that, though students are prepared for the examinations of the City and Guilds of London Institute, the Hotel and Catering Institute and other bodies, the principle purpose of both full and part-time courses is not merely 
examination successes but training for a useful and successful career in the chosen section of the industry.

Technical colleges enjoy great independence in the framing of teaching syllabuses and in teaching. Thus there is inevitably a difference between them in emphasis on various subjects. It would, however, be safe to say that all those responsible for work in Hotel and Catering Departments attach the greatest importance to a study of the underlying principles of food preparation and cookery. It is accepted that students should understand the reasons for carrying out various processes, and thus the teaching of simple nutrition inevitably forms the theoretical basis of much of the instruction.

This teaching remains a feature of cookery classes after the student has passed the 'I 50' stage; it may be, however, that the subject tends to assume a diminishing importance for those who after their basic training continue with courses in hotel book-keeping and reception, licensed house work, waiting, or more advanced cookery, such as the City and Guilds of London Institute ' 15 I' Cookery for Hotels and Catering Establishments, and ' 152 ' Advanced Cookery for Hotels and Restaurants.

\section{Nutrition in advanced training}

Those who aspire to executive posts in the Hotel and Catering Industry, however, are now encouraged to prepare for the Hotel and Catering Institute's A.M.H.C.I. examination as the first stage. In addition most full-time courses conducted in Hotel and Catering subjects at Technical Colleges culminate in a College Certificate or Diploma besides the various specialized National Certificates in craft subjects. The scope varies from college to college, but all those who continue in full-time training, after completing their ist year of basic catering training, will likewise continue their study of nutrition, certainly in so far as it is a necessary concomitant of intelligent instruction in cookery and also as a subject in itself, to provide for those who, on completion of their training, will need a sound grasp of the subject in order to follow a useful career in hospital, institutional and industrial catering.

The Hotel and Catering Institute cannot claim to have sponsored the courses leading to the examinations conducted by the Institutional Management Association, in which the teaching of nutrition has been described by Miss Lumby (1953). It should, however, be emphasized that the Institute has a keen interest in the training of those seeking a career in the institutional management field and is closely associated with the I.M.A. in the further development of such training. The Institute recognizes certificates gained by candidates for the I.M.A. examinations and accepts them in part qualification for professional status as Associate Members.

\section{Teaching the teacher}

Significant of the importance attached to the teaching of nutrition in courses sponsored by the Hotel and Catering Institute is the time that has been devoted to 
nutrition in short courses arranged for specialist teachers of catering subjects. In July last year, for example, catering teachers from the south of England attended a short course on The Scientific Principles of Nutrition arranged at the Northern Polytechnic, London. The course included lectures by nutrition experts and intentionally covered a wide field, for it had as one of its objectives the aim of showing the teacher both the vastness of the subject and the dangers of incomplete knowledge.

In the short courses for teachers arranged by the Ministry of Education in conjunction with the Hotel and Catering Institute, methods of teaching science and nutrition to catering students have invariably been given a prominent place in lectures and discussions.

Short courses for teachers are of particular value and importance now because, as already mentioned, the development of hotel and catering education has been wide and rapid, and it has not been easy to meet the comparatively sudden and widespread need for qualified teachers.

The establishment of such courses for teachers has an important bearing on the teaching of nutrition; the industry's difficulty in finding enough persons competent to teach craft subjects, such as cookery, to a high level, and to instruct in underlying theories and basic principles, will be readily appreciated. The teaching of catering subjects during the early days was in many centres shared between recruits from industry, who dealt with higher aspects of craftsmanship and industrial techniques, and teachers with domestic science qualifications, who augmented the instruction in theoretical subjects, such as nutrition. Among the aims of short courses, therefore, has been that of widening the ability of the trade teacher to deal with basic principles underlying his craft and to enlarge the scope of the domestic science teacher in relation to trade practices.

The trade teacher must necessarily approach the subject of nutrition with some caution, but it is clear that his interest is now aroused; he is aware of the vital importance of nutrition, and this interest and awareness will in time be communicated to the industry as a whole. This is one of the many valuable contributions that a properly developed system of technical education will bring to the industry itself.

\section{Widening the caterer's sphere}

Many sections of the industry are hopeful that the development of a technical education system will enable caterers of the right calibre and training to equip themselves further through postgraduate courses or dual purpose courses for careers as dietitian caterers. There is undoubtedly a widespread feeling, particularly amongst those who cater in hospitals, that the differences in many institutions between executive control of dietetics and catering is unsound. A dietitian entering welfare or hospital catering has often to learn catering techniques, and it is felt that, conversely, the caterer, if having the right background, must be able to learn nutrition to a more advanced level than in the past and qualify in some measure both as dietitian and as caterer. Such aspirations are undoubtedly being stimulated, 
though not necessarily of intention, by the hotel and catering courses developed largely through the work of the Institute and its predecessors.

It is perhaps legitimate to touch upon the aspirations stimulated by these courses, because the teaching of subjects such as nutrition to students and teachers is undoubtedly creating a new climate of opinion in the industry itself. The industry, through its students and teachers, has been brought in touch with many of the principles underlying their work, which had previously received but cursory attention. Hygiene, nutrition, and science are today subjects of significance, not only in the curricula of technical colleges, but in the programmes of practical hotel keepers and caterers themselves. The industry has rubbed shoulders with teachers of domestic science, teachers of nutrition and teachers of accounts and other subjects, and there has been give and take on both sides. The Institute, representing the industry, foresees and hopes for the day when the teaching of hotel and catering subjects will be entirely in the hands of those properly trained in the industry and as teachers, but meanwhile it recognizes the vast debt it owes for help from teachers in other fields, particularly domestic science. It has profited from this give and take, and it is certain that, among the many subjects given heightened significance by these contacts, nutrition is prominent.

\title{
REFERENCE
}

Lumby, A. (1953). Proc. Nutr. Soc., 12, 186.

\section{The Royal Sanitary Institute Certificate in Nutrition}

\author{
By H. E. Magee, Ministry of Health, 23 Savile Row, London, W.I
}

\begin{abstract}
Postwar need
Towards the end of World War II it became increasingly evident that courses in elementary nutrition and dietetics were needed for people who had been concerned in one way or another with community feeding, as in industrial and other canteens, in hospitals and schools and residential institutions. It soon became clear that the demand for such courses would increase with the end of the war. The anticipation proved to be true and large numbers of demobilized men and women, who had been working at catering, cooking or serving food in messes, hospitals and canteens, made it known that they would welcome instruction of a practical nature in nutrition and dietetics. Technical schools and institutes were obviously the most suitable places for their purpose, and inquiries made in some of them showed that they would welcome the chance to give such courses provided it would lead, after a suitable examination, to a certificate or diploma conferred by a responsible and authoritative organization. The Royal Sanitary Institute on being approached by The Nutrition Society in January 1945 expressed its willingness to conduct examinations in several centres throughout the country and to award an official certificate of the
\end{abstract}

